15

\title{
Синтез и исследование нанопорошков и керамики магний-алюминиевой шпинели, активированной медью
}

\author{
(C) В.В. Осипов, ${ }^{1}$ В.И. Соломонов, ${ }^{1,2}$ А.В. Подкин, ${ }^{1}$ В.А. Шитов, ${ }^{1}$ Е.В. Тихонов, ${ }^{1}$ А.С. Корсаков ${ }^{2}$ \\ ${ }^{1}$ Институт электрофиизики УрО РАН, \\ 620016 Екатеринбург, Россия \\ 2 Уральский федеральный университет им. первого Президента России Б.Н. Ельцина, \\ 620002 Екатеринбург, Россия \\ e-mail: plasma@iep.uran.ru
}

Поступило в Редакцию 3 февраля 2020 г.

В окончательной редакции 26 мая 2020 г.

Принято к публикации 26 мая 2020 г.

Методом лазерного испарения твердой мишени, представляющей собой механическую смесь простых оксидов $\left(\mathrm{MgO}, \mathrm{Al}_{2} \mathrm{O}_{3}, \mathrm{CuO}\right)$, получены нанопорошки, представленные двумя кристаллическими фазами: магний-алюминиевая шпинель $(98 \mathrm{wt} . \%)$ и куприт $(2 \mathrm{wt} . \%)$. Из этих нанопорошков изготовлены пробные образцы прозрачной керамики $\mathrm{Cu}: \mathrm{MgAl}_{2} \mathrm{O}_{4}$, в ИК спектрах пропускания которых обнаружены две новые сильные полосы поглощения при $\lambda_{1} \approx 1.55(1.45)$ и $\lambda_{2} \approx 3.45(3.03) \mu \mathrm{m}$, соответствующие переходам между штарковскими уровнями ${ }^{2} \mathrm{E}\left(\mathrm{t}_{2}^{6} \mathrm{e}^{3}\right)$ и ${ }^{2} \mathrm{~T}_{2}\left(\mathrm{t}_{2}^{5} \mathrm{e}^{4}\right)$ ионов $\mathrm{Cu}^{2+}$ в октаэдрической и тетраэдрической позициях соответственно.

Ключевые слова: магний-алюминиевая шинель, ион меди, нанопорошок, керамика, ИК спектр пропускания, полосы поглощения иона меди.

DOI: $10.21883 / J T F .2021 .01 .50289 .94-20$

\section{Введение}

Область длин волн среднего инфракрасного диапазона 2-5 $\mathrm{m}$ представляет значительный интерес, так как соответствует окну прозрачности земной атмосферы и максимуму поглощения биологических тканей $(\sim 2.9 \mu \mathrm{m})$. В настоящее время этот диапазон длин волн осваивается твердотельными лазерами на переходах между штарковскими уровнями ионов-активаторов переходных металлов $\mathrm{Fe}^{2+}, \mathrm{Co}^{2+}$ и $\mathrm{Cr}^{2+}$, расположенных в тетраэдрических позициях кристаллической матрицы.

Наилучшие результаты получены при использовании монокристаллов и поликристаллов халькогенидов цинка $\mathrm{ZnSe}$ и $\mathrm{ZnS}$, легированных указанными активаторами. Впервые лазерный эффект на кристаллах $\mathrm{Cr}^{2+}: \mathrm{ZnSe}$ и $\mathrm{Cr}^{2+}: \mathrm{ZnS}$ на длинах волн 2.1-3.1 $\mu \mathrm{m}$ был получен в 1996 г. [1]. Интенсивное исследование этих сред привело к достижению средней мощности до $140 \mathrm{~W}$ [2] и энергии в импульсе до $1.1 \mathrm{~J}$ [3]. Лазерный эффект на кристаллах $\mathrm{Fe}^{2+}: \mathrm{ZnSe}$ в диапазоне длин волн 3.98-4.54 $\mu \mathrm{m}$ впервые получен в [4]. На сегодняшний день средняя мощность $\mathrm{Fe}^{2+}: \mathrm{ZnSe}$ лазеров составляет $20 \mathrm{~W}$, а энергия в импульсе - 10.6 и $7.5 \mathrm{~J}$ при охлаждении жидким азотом и элементом Пельтье соответственно [5]. $\mathrm{B}$ работе [5] легирование матрицы $\mathrm{ZnSe}$ ионами железа осуществлялось за счет термодиффузии. Существенными недостатками этого метода являются малая глубина активации и неоднородное распределение активаторов по глубине с максимумом у поверхности. Последний эффект приводит к возникновению паразитной поперечной люминесценции, снижающей эффективность лазера. Для его ослабления в [6] использовали активный элемент $\mathrm{Fe}^{2+}: \mathrm{ZnSe}$ с внутренним легированным слоем в виде мениска. Это привело к увеличению эффективности лазера на 19\% по сравнению с активными элементами с одним плоским легированным слоем.

Проводятся исследования по использованию других методов активации кристаллов двухвалентными ионами железа. В [7] вертикальным методом Бриджмена были выращены монокристаллы $\mathrm{Fe}^{2+}: \mathrm{ZnSe}$ с однородным распределением железа, предварительно введенного в расплав в виде FeSe. На выращенных кристаллах при концентрации ионов железа $n_{\mathrm{Fe}}=6.4 \cdot 10^{18} \mathrm{~cm}^{-3}$ была получена энергия лазерного излучения $870 \mathrm{~mJ}$ при КПД по отношению к поглощенной мощности накачки HF-лазером, равном 43\%, а на кристаллах с $n_{\mathrm{Fe}}=5.7 \cdot 10^{19} \mathrm{~cm}^{-3}$ приблизительно в тех же условиях получено $245 \mathrm{~mJ}$ и $22 \%$ соответственно. Меньшие значения энергетических параметров лазера при повышенной концентрации железа обусловлены небольшой глубиной накачки около $200 \mu \mathrm{m}$, обусловленной повышенной концентрацией ионов железа. Остальная часть кристалла частично поглощала лазерное излучение.

Перспективным материалом для активных элементов лазеров с длиной волны излучения $2-5 \mu \mathrm{m}$ является магний-алюминиевая шпинель $\mathrm{MgAl}_{2} \mathrm{O}_{4}$, прозрачная в диапазоне 2.5-6.5 $\mu \mathrm{m}$ [8]. Однако монокристаллы $\mathrm{Fe}^{2+}: \mathrm{MgAl}_{2} \mathrm{O}_{4}$ высокого оптического качества трудно вырастить из-за высокой температуры плавления шпинели $2135^{\circ} \mathrm{C}$ и низкой растворимости ионов железа в шпинели. Для активации железом шпинели в [9] использовался метод термодиффузии ионов железа в 
исходный номинально чистый кристалл $\mathrm{MgAl}_{2} \mathrm{O}_{4}$. Показано, что в получившемся монокристалле $\mathrm{Fe}: \mathrm{MgAl}_{2} \mathrm{O}_{4}$ ионы железа находятся в двухвалентном состоянии и имеют широкую полосу люминесценции в области 3-6 $\mu \mathrm{m}$. В [10] синтезировали оптическую керамику $\mathrm{Fe}^{2+}: \mathrm{MgAl}_{2} \mathrm{O}_{4}$ с равномерным распределением двухвалентного железа с концентрацией $n_{\mathrm{Fe}} \sim 2.8 \cdot 10^{19}$, $2.8 \cdot 10^{20}$ и $1.4 \cdot 10^{21} \cdot \mathrm{cm}^{-3}$. Керамика синтезировалась из наноразмерных порошков, полученных методом лазерного испарения мишени заданного химического состава [11]. Достоинством такого метода является возможность получения сложных оксидов путем испарения механической смеси соответствующих простых оксидов. При этом при конденсации пара в наночастицах образуется кристаллическая решетка со стехиометрией, соответствующей мольному составу испаренной смеси, а примесные ионы-активаторы образуют твердый раствор.

Перспективным ионом-активатором для получения лазерной генерации в средней ИК области является двухвалентный ион меди $\mathrm{Cu}^{2+}$ с электронной конфигурацией $3 d^{9}$. Этой конфигурации соответствует только один терм ${ }^{2} \mathrm{D}$. В тетраэдрическом поле он расщепляется на орбитальный дублет ${ }^{2} \mathrm{E}\left(\mathrm{t}_{2}^{6} \mathrm{e}^{3}\right)$ и триплет ${ }^{2} \mathrm{~T}_{2}\left(\mathrm{t}_{2}^{5} \mathrm{e}^{4}\right)$. Однако в кристаллах $\mathrm{ZnS}$ и $\mathrm{ZnSe}$ ион меди в таком виде не проявляется. В частности, в кристаллах $\mathrm{ZnSe}$ ионы меди образуют ассоциативные Cu-центры, включающими в себя кислород [12]. Такие кристаллы, активированные медью, являются эффективными люминофорами зеленого излучения. В [13] исследовали процесс импульсной имплантации ионов меди $\mathrm{Cu}^{2+}$ в прозрачную магнийалюминиевую шпинель с целью создания наночастиц меди в поверхностном слое керамики. В этой работе показано, что максимальная концентрация ионов $\mathrm{Cu}^{2+}$ в поверхностном слое керамики эффективной глубиной $20 \mathrm{~nm}$ достигает $5 \cdot 10^{21} \mathrm{~cm}^{-3}$. При превышении этой величины ионы меди коагулируют в металлические наночастицы. Этот факт указывает на высокую растворимость ионов $\mathrm{Cu}^{2+}$ в матрице магний-алюминиевой шпинели при таком методе допирования. Публикаций по активации магний-алюминиевой шпинели ионами двухвалентного железа и меди другими методами нами не обнаружено.

В настоящей работе представлены результаты получения и исследования нанопорошка, полученного методом испарения импульсно-периодическим $\mathrm{CO}_{2}(\lambda=10.6 \mu \mathrm{m})$ лазером твердой мишени из механической смеси микроразмерных порошков $\mathrm{MgO}, \mathrm{Al}_{2} \mathrm{O}_{3}$ и $1 \mathrm{~mol} \% \mathrm{CuO}$, a также изготовленных из этих нанопорошков пробных образцов керамики $\mathrm{Cu}^{2+}: \mathrm{MgAl}_{2} \mathrm{O}_{4}$.

\section{1. Аппаратура и методы анализа нанопорошков и керамики}

Нанопорошки магний-алюминиевой шпинели, допированные ионами меди, были приготовлены с помощью импульсно-периодического $\mathrm{CO}_{2}$-лазера „ЛАЭРТ“. Метод заключается в испарении лазерным излучением мишени, приготовленной из смеси микропорошков соответствующих простых оксидов и последующей конденсации паров в потоке воздуха. Экспериментальная установка подробно описана в $[10,11] . \mathrm{CO}_{2}$-лазер $(\lambda=10.6 \mu \mathrm{m})$ генерировал импульсы излучения длительностью $370 \mu \mathrm{s}$ на полувысоте с частотой повторения $500 \mathrm{~Hz}$. Пиковая мощность импульсов составляла $7.2 \mathrm{~kW}$ при средней мощности излучения $\approx 300 \mathrm{~W}$. Перед началом работы мишень устанавливалась в перетяжку лазерного пучка, сфокусированного с помощью линзы с фокусным расстоянием $107 \mathrm{~mm}$. Лазерное пятно в фокусе линзы имело два максимума интенсивности лазерного излучения, которые перекрывались и вписывались в эллипс размерами $0.6 \times 0.9 \mathrm{~mm}$. Соответственно плотность мощности излучения, усредненная по пятну, была равна $1.7 \cdot \mathrm{MW} / \mathrm{cm}^{2}$. Механизм подачи мишени обеспечивал ее движение таким образом, чтобы по мере испарения мишени положение ее поверхности оставалось в плоскости перетяжки лазерного луча, а относительное движение лазерного луча по поверхности мишени осуществлялось по спирали со скоростью $35 \mathrm{~cm} / \mathrm{s}$, обеспечивая ее равномерный износ.

Мишень была изготовлена из коммерческих микроразмерных порошков $\mathrm{Al}_{2} \mathrm{O}_{3}, \mathrm{MgO}$ и $\mathrm{CuO}$ чистотой 99.99, 99.5 и 99.3 wt.\% соответственно. Нужная пропорция смеси достигалась путем взвешивания отдельных оксидов на электронных весах. Предварительно для удаления летучих веществ, каждый оксид отжигался на воздухе при температуре $1000^{\circ} \mathrm{C}$ в течение $3 \mathrm{~h}$. Затем смесь перемешивалась в течение $26 \mathrm{~h}$ и дополнительно измельчалась до микронных размеров с помощью механической мельницы. Полученный микропорошок одноосно прессовался в таблетку, которая спекалась при температуре $1300^{\circ} \mathrm{C}$ в течение $5 \mathrm{~h}$ при атмосферном давлении. Для приготовления пробных образцов керамики нанопорошки компактировались в диски диаметром $\varnothing 14.4 \mathrm{~mm}$ и толщиной 2-2.5 mm одноосным статическим прессом при давлении $200 \mathrm{MPa}$. Плотность компактов составляла около $50 \%$ от теоретического значения плотности шпинели $\left(3.72 \mathrm{~g} / \mathrm{cm}^{3}\right)$. Спекание компактов проводилось в воздушной печи с хром-лантановым нагревателем при температурах 1400 и $1450^{\circ} \mathrm{C}$, а также в вакуумной печи при температуре $1450^{\circ} \mathrm{C}$. В обоих случаях скорость нарастания температуры составляла $5 \mathrm{~K} / \mathrm{min}$, остывания $20 \mathrm{~K} / \mathrm{min}$, выдержка $1 \mathrm{~h}$.

Измерение катионного состава лазерной мишени и нанопорошков проводилось методом атомно-эмиссионного спектрального анализа с индуктивно-связанной плазмой на спектрометре Optima 2100. Определение фазового состава нанопорошков и керамики производилось методом рентгенофазового анализа (РФА) на дифрактометре D8 DISCOVER $\left(K_{\alpha 1,2}(\mathrm{Cu}), \lambda=0.1542 \mathrm{~nm}\right)$. Удельная поверхность наночастиц определялись ВЕТ методом на анализаторе TriStar3000. Измерения спектров пропускания производились при комнатной температуре на спектрофотометре Shimadzu UV-1700 (Shimadzu Corp., Япо- 
ния) в диапазоне 200-1100 nm и с помощью ИК Фурье спектрометра IRPrestige-21 (Shimadzu Corp., Япония) в диапазоне от 1.28 до $28.5 \mu \mathrm{m} \mathrm{c}$ разрешением $4 \mathrm{~cm}^{-1}$. При измерениях на ИК спектрометре использовался делитель из $\mathrm{KBr}$, детектор DLaTGS (дейтерированный триглицинсульфат, легированный $L$-аланином), источник ИК излучения - глобар, количество сканирований фона и образцов - 20. Образцы керамики перед оптическими измерениями подвергались предварительной ручной шлифовке алмазной пастой.

\section{2. Результаты и обсуждение}

Производительность получения нанопорошка оказалась равной $12.6 \mathrm{~g} / \mathrm{h}$. Нанопорошок представлял собой слабоагломерированные частицы почти сферической формы. Его удельная поверхность составляла $55.5 \mathrm{~m}^{2} / \mathrm{g}$, что соответствует среднемассовому размеру наночастиц $d_{B E T} \approx 30 \mathrm{~nm}$, при этом средний арифметический размер наночастиц был около $18 \mathrm{~nm}$.

Катионный состав лазерной мишени до испарения и полученного из нее нанопорошка, приведен в таблице. Содержание летучих компонент составляло 0.8 и 10.6 wt.\% в мишени и нанопорошке соответственно.

Отличие катионных составов нанопорошка и исходной мишени является типичной ситуацией при получении наночастиц сложных оксидов методом лазерного испарения смеси простых оксидов [11,14]. Ее причина заключается в различии температур плавления и кипения оксидов. Различию катионного состава нанопорошков и мишени способствует также выдавливание жидкости из лазерного кратера и ее разбрызгивание из расплава, уже обедненного более легкоплавкими компонентами $[11,14]$. Это усложняет картину лазерного испарения смеси этих трех оксидов. Вышеназванные причины приводят к тому, что содержание паров оксидов в потоке лазерного факела отличается от их содержания в мишени. В данном случае имеет место наименьший поток паров оксида алюминия, что приводит к увеличению доли катионов магния и меди в нанопорошке (см. таблицу). Аналогичное увеличение доли катионов магния и железа нами наблюдалось ранее при лазерном синтезе нанопорошка магний-алюминиевой шпинели, допированной ионами железа [11]. Тем не менее при одинаковых условиях испарения, но различающегося количественного состава компонентов мишени, имеет место устойчивая корреляционная связь между количественным содержанием ка-

Катионный состав исходной мишени и нанопорошков в at.\%

\begin{tabular}{c|c|c}
\hline Элемент & Мишень & Нанопорошок \\
\hline $\mathrm{Cu}$ & 0.54 & 0.62 \\
$\mathrm{Al}$ & 67.11 & 64.39 \\
$\mathrm{Mg}$ & 32.35 & 34.39
\end{tabular}

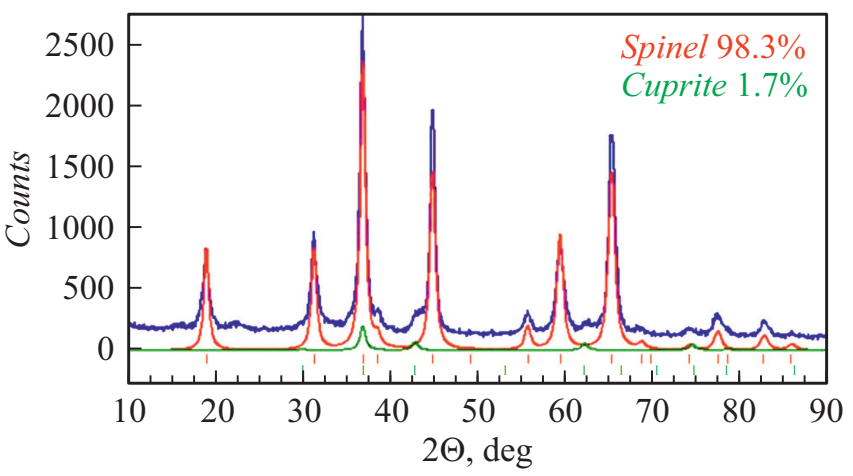

Рис. 1. Дифрактограмма нанопорошков. Ниже нуля приведены стандартные шкалы рефлексов магний-алюминиевой шпинели (верхняя красная) и куприта (нижняя зеленая) (в on-line версии).

тионов в мишени и в нанопорошке. Этот факт позволит получать нанопорошки заданного химического состава.

РФА показал (рис. 1), что нанопорошок состоит на 98 wt.\% из шпинели с периодом кристаллической решетки $a=0.8069 \pm 0.0002 \mathrm{~nm}$ с областью когерентного рассеяния (ОКР) $13 \pm 2 \mathrm{~nm}$. Однако в нем присутствует вторая фаза куприт $\left(\mathrm{Cu}_{2} \mathrm{O}\right)$ с периодом кубической решетки $a=0.4215 \pm 0.0008 \mathrm{~nm}$ и ОКР $-11 \pm 2 \mathrm{~nm}$. Еe содержание, около $2 \mathrm{wt.} \%$, приблизительно соответствует содержанию, введенной в лазерную мишень меди (см. таблицу). Т.е. в нанопорошке большая часть введенной в мишень меди выделилась в отдельную фазу - куприт. Причем, судя по величине ОКР, эта фаза формируется в отдельные наночастицы, а не входит в состав единых частиц. Выделение куприта в отдельную фазу связано с физико-химическими процессами формирования наночастиц в лазерном факеле. Их интенсивное образование начинается в областях факела, в которых температура пара снизилась до температуры плавления высокотемпературных оксидов: $\mathrm{MgO}$ $\left(T_{m}=2825^{\circ} \mathrm{C}\right) \mathrm{Al}_{2} \mathrm{O}_{3}\left(T_{m}=2046^{\circ} \mathrm{C}\right)$ [15]. Эта температура превышает температуру диссоциации оксида меди $\mathrm{Cu}_{2} \mathrm{O}\left(T_{d}=1800^{\circ} \mathrm{C}\right)$ [15]. Поэтому в этих областях факела пары меди присутствуют в основном в виде нейтральных атомов и частично ионов и конденсируются в последнюю очередь. При значительном содержании кислорода в потоке несущего газа они окисляются до состояния $\mathrm{Cu}_{2} \mathrm{O}$, что затрудняет их внедрение в уже, практически, сформировавшуюся кристаллическую решетку шпинели (полное время образования и остывания наночастиц составляет нескольких миллисекунд [16]) и приводит к формированию отдельной фазы куприта. Подобное наблюдалось нами ранее при получении с помощью волоконного иттербиевого лазера нанопорошка магний-алюминиевой шпинели, допированной ионам $\mathrm{Fe}^{2+}[11]$. В последнем случае оксид железа в нанопорошке присутствовал в виде фазы магнетита $\left(\mathrm{Fe}_{3} \mathrm{O}_{4}\right)$, как продукт термодиссоциации $\mathrm{Fe}_{2} \mathrm{O}_{3}$. 


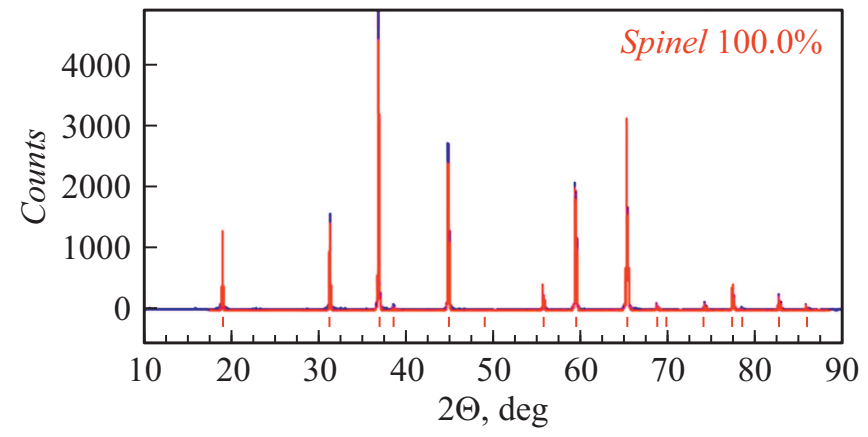

Рис. 2. Дифрактограмма керамики состава $\mathrm{Cu}: \mathrm{MgAl}_{2} \mathrm{O}_{4}$, спеченной в воздушной печи при температуре $1450^{\circ} \mathrm{C}$. Ниже нуля приведена стандартная шкала рефлексов магний-алюминиевой шпинели.

Заметное отличие периодов решеток обеих фаз нанопорошка от стандартных значений $\left(a_{s t}=0.80831 \mathrm{~nm}\right.$ для $\mathrm{MgAl}_{2} \mathrm{O}_{4}$, PDF № 21-1152, и $a_{s t}=0.42696 \mathrm{~nm}$ для $\mathrm{Cu}_{2} \mathrm{O}$, PDF № 05-0667) свидетельствует о том, что в кристаллических решетках обеих фаз присутствуют искажения и неоднородности анионного и катионного составов. В частности, согласно катионному составу нанопорошка (см. таблицу), присутствующая в нем фаза шпинели содержанием $98 \mathrm{wt} . \%$ имеет брутто формулу $\mathrm{Cu}_{x} \mathrm{Mg}_{1.088} \mathrm{Al}_{2} \mathrm{O}_{4.088-x}$, где $x$ - число атомов меди в формульной единице.

Образцы керамики, спеченные из этого нанопорошка на воздухе при температуре $1400^{\circ} \mathrm{C}$, оказались непрозрачными, а при температуре $1450^{\circ} \mathrm{C}-$ полупрозрачными в видимой области спектра. В то же время оба этих типа керамики оказались однофазными. Для иллюстрации на рис. 2 представлена дифрактограмма керамики, спеченной в воздухе при температуре $1450^{\circ} \mathrm{C}$ в течение $1 \mathrm{~h}$. В обоих образцах керамики кристаллическая фаза представляет собой $\mathrm{MgAl}_{2} \mathrm{O}_{4}$-шпинель, но с разными постоянными кристаллической решетки $a=0.8082 \pm 0.0002$ и $0.8075 \pm 0.0004 \mathrm{~nm}$ и областями когерентного рассеяния 58 и $550 \mathrm{~nm}$ для образцов керамики, спеченных при температурах 1400 и $1450^{\circ} \mathrm{C}$ соответственно. На порядок меньшая ОКР керамики, спеченной при $1400^{\circ} \mathrm{C}$, указывает на то, что в ней кристаллиты имеют меньшие размеры, а непрозрачность ее в видимой области указывает на повышенную дефектность межкристаллитных границ. Повышенная по сравнению с нанопорошком постоянная решетки указывает на то, что в керамике ионы меди из фазы куприта нанопорошка в керамике диффундировали в шпинель.

В образцах керамики, спеченных в вакууме при температуре $1450^{\circ} \mathrm{C}$, кроме шпинели, содержанием более $99 \mathrm{wt} . \%$ с постоянной решетки $a=0.8070 \pm 0.003 \mathrm{~nm}$ и ОКР $430 \mathrm{~nm}$, обнаружены следы (менее $0.5 \mathrm{wt} \%$ ) металлической меди в кубической фазе с постоянной решетки $a=0.3622 \pm 0.0008 \mathrm{~nm}$. Постоянные решетки шпинели этих образцов и нанопорошков в пределах точности измерения совпадают. Эти два факта указывают на то, что при вакуумном спекании нанопорошков в керамике почти весь куприт восстанавливается до металлической меди за счет термической диссоциации. При этом часть атомов меди из разложившегося куприта входит в состав керамики в виде наночастиц металлической меди, и лишь небольшая часть ионов меди дополнительно входят в решетку шпинели. На это указывает сравнение спектров пропускания керамик в ИК области.

На рис. 3 приведены спектры пропускания нанопорошка (кривая 1) и керамических образцов, спеченных на воздухе (кривая 2) и в вакууме (кривая 3) при температуре $1450^{\circ}$. Разрыв спектров в области $1.1-1.28 \mathrm{~nm}$ обусловлен несовпадением длинноволновой и коротковолновой границ регистрации спектров двумя разными спектрофотометрами. В спектре нанопорошка отчетливо проявляются полосы поглощения воды на длинах волн валентных $(3 \mu \mathrm{m})$ и деформационных $(6.1 \mu \mathrm{m})$ колебаний, а также прослеживаются более слабые пики поглощения воды на длинах волн 1.4 и 1.9 mит. Их наличие связано с тем, что нанопорошок является хорошим геттером воды, а она всегда присутствует в нем как летучая компонента.

В спектрах пропускания керамики, спеченной на воздухе (кривая 2), наблюдаются две сильные полосы поглощения с центрами при $\lambda_{1} \approx 1.55$ и $\lambda_{2} \approx 3.45 \mu \mathrm{m}$. Подобные, но смещенные в коротковолновую сторону полосы поглощения $\left(\lambda_{1} \approx 1.45, \lambda_{2} \approx 3.05 \mu \mathrm{m}\right)$ наблюдаются в керамике, спеченной в вакууме (кривая 3 ). В спектрах пропускания нанопорошка (кривая 1) с ними коррелируют снижения пропускания в областях $1.2-2.0$ и $4.0-5.5 \mu \mathrm{m}$. В [17] при исследовании $\mathrm{ZnO}-\mathrm{TeO}_{2}$-стекол, активированных ионами $\mathrm{Cu}^{2+}$, также наблюдали две широкие полосы поглощения, но при $\lambda=820 \mathrm{~nm}$ и $3.3 \mu \mathrm{m}$. Из них первую $(820 \mathrm{~nm})$ авторы [17] однозначно связали с поглощением иона меди $\mathrm{Cu}^{2+}$ в кристаллическом поле силой $\Delta_{c r}=12200 \mathrm{~cm}^{-1}$. В ней поглощение сильно

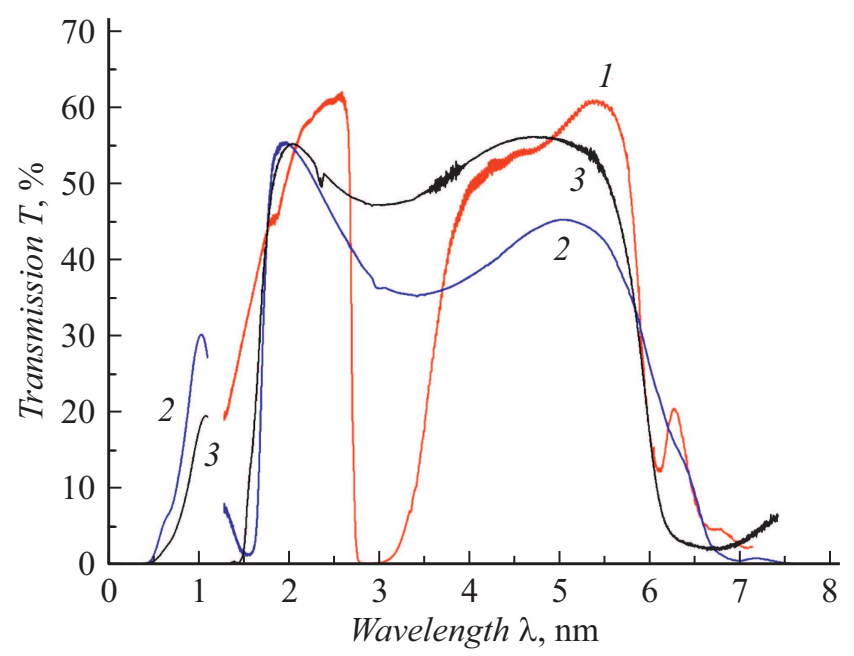

Рис. 3. Спектры пропускания нанопорошка (1) и керамики, спеченной в воздухе (2) и в вакууме (3) при температуpe $1450^{\circ} \mathrm{C}$. 
нарастало с ростом концентрации ионов меди. Поглощение во второй полосе $(3.3 \mu \mathrm{m})$ почти не зависело от содержания меди. Ее природу авторы [17] связывают с

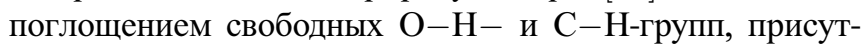
ствующих в стеклах из-за несовершенства технологии их приготовления.

В нашем случае вторая полоса поглощения при $\lambda_{2} \approx 3.45(3.05) \mu \mathrm{m}$ по форме и спектральному положению почти совпадает с полосой при $\lambda \approx 3.3 \mu \mathrm{m} \mathrm{в} \mathrm{[17].}$ Частоты локальных колебаний радикальных групп О-H и $\mathrm{C}-\mathrm{H}$ попадают в диапазон этой полосы, но они сосредоточены в более узких областях спектра. В спектре пропускания керамики (кривые 2,3) они проявляются в виде слабых (на уровне шума) пиков при 2.97-3.1 $\mu \mathrm{m}$ $(\mathrm{O}-\mathrm{H})$ и $3.4-3.5 \mu \mathrm{m}(\mathrm{C}-\mathrm{H})$. Более наглядно эти радикальные группы проявляется в спектре пропускания нанопорошка (кривая 1), образуя общую сильную полосу поглощения, шириной значительно меньше полосы поглощения при $\lambda_{2} \approx 3.45(3.15) \mu \mathrm{m}$ керамики.

Обращает на себя внимание хорошее совпадение отношений длин волн центров полос поглощения в обоих типах керамики $\lambda_{1} / \lambda_{2}=4 / 9$ с отношением сил кристаллических полей в тетраэдрической и октаэдрической позициях $\left(\Delta_{t e t r} / \Delta_{o k t}=4 / 9\right)$. Отсюда следует, что полоса при $\lambda_{1}$ соответствует поглощению иона меди $\mathrm{Cu}^{2+}$ в октаэдрической, а при $\lambda_{2}-$ в тетраэдрической позициях. Причем, силы этих полей в керамиках, спеченных в разных условия, заметно отличаются. По данным рис. 3 они равны $\Delta_{\text {okt }} \approx 6450$ и $\Delta_{\text {tetr }} \approx 2900 \mathrm{~cm}^{-1}$ для керамики, спеченной в воздухе, и $\Delta_{o k t} \approx 6896$ и $\Delta_{t e t r} \approx 3300 \mathrm{~cm}^{-1}$ для керамики, спеченной в вакууме. Это различие обусловлено различием дефектного состава керамик в окружении примесных ионов меди. В частности, в керамике, спеченной в вакууме, реализуется повышенное содержание анионных вакансий за счет частичного испарения кислорода.

Двухвалентный ион меди $\mathrm{Cu}^{2+}$ с электронной конфигурацией $3 d^{9}$ образует единственный терм ${ }^{2} \mathrm{D}$. В тетраэдрическом кристаллическом поле этот терм расщепляется на орбитальный дублет ${ }^{2} \mathrm{E}\left(\mathrm{t}_{2}^{6} \mathrm{e}^{3}\right)$ (нижний) и триплет ${ }^{2} \mathrm{~T}_{2}\left(\mathrm{t}_{2}^{5} \mathrm{e}^{4}\right)$ (верхний), а в октаэдрическом расположение уровней противоположно. Наблюдаемые на этих переходах полосы поглощения имеют большие ширины, которые на полувысоте имеют значения $\Delta v_{1} \approx 2500$ и $\Delta v_{2} \approx 1500 \mathrm{~cm}^{-1}$. Это уширение, в первую очередь, обусловлено расщеплением штарковских уровней на два подуровня за счет спин-орбитального взаимодействия. То есть каждая наблюдаемая полоса поглощения при $\lambda_{1}$ и $\lambda_{2}$ представляет собой суперпозицию двух полос, обусловленных спин-орбитальным расщеплением штарковских уровней. При комнатной температуре за счет электрон-фононного взаимодействия эти компоненты сливаются, образуя общую уширенную полосу. Для уточнения структуры энергетических уровней необходимо повысить оптическое качество керамики, провести измерения ее пропускания при криогенной температуре и зафиксировать люминесценцию на этих переходах. Эти данные позволят сделать однозначный вывод о перспективности системы $\mathrm{Cu}^{2+}: \mathrm{MgAl}_{2} \mathrm{O}_{4}$ для получения лазерной генерации на переходах иона $\mathrm{Cu}^{2+}$ в средней ИК области спектра.

\section{Заключение}

Таким образом, метод лазерного испарения твердой мишени, представляющей собой механическую смесь простых оксидов, позволяет получать нанопорошки, из которых можно изготовлять оптическую керамику на основе магний-алюминиевой шпинели, активированной двухвалентными ионами меди.

В ИК спектрах пропускания пробных образцов керамики $\mathrm{Cu}^{2+}: \mathrm{MgAl}_{2} \mathrm{O}_{4}$ впервые обнаружены две сильные полосы поглощения при $\lambda_{1} \approx 1.55$ и $\lambda_{2} \approx 3.45 \mu \mathrm{m}-$ в керамике, спеченной на воздухе, и при $\lambda_{1} \approx 1.45$ и $\lambda_{2} \approx 3.05 \mu \mathrm{m}-$ в керамике, спеченной в вакууме, соответствующие переходам между штарковскими уровнями ${ }^{2} \mathrm{E}\left(\mathrm{t}_{2}^{6} \mathrm{e}^{3}\right)$ ионов $\mathrm{Cu} 2+$ в октаэдрической и тетраэдрической позициях.

Для получения керамики высокого оптического качества на основе магний-алюминиевой шпинели, активированной ионами меди, следует уменьшить содержание активаторов, так как их избыточное содержание приводит к созданию дефектов, в том числе и в виде наночастиц металлической меди, снижающих прозрачность керамики.

\section{Финансирование работы}

Работа выполнена в рамках проекта РФФИ № 20-0800054 в части активации медью шпинели и исследования ее свойств и в рамках госбюджета ИЭФ УрО РАН в части синтеза керамической шпинели.

\section{Конфликт интересов}

Авторы заявляют, что у них нет конфликта интересов.

\section{Список литературы}

[1] L.D. DeLoach, R.H. Page, C.D. Wilke, S.A. Payne, W.F. Krupke. IEEE J. Quant. Electr., 32 (6), 885 (1996).

[2] I. Moskalev, S. Mirov, M. Mirov, S. Vasilyev, V. Smolski, A. Zakrevskiy, V. Gapontsev. Opt. Express, 24, 21090 (2016).

[3] V.V. Fedorov, M.S. Mirov, S.B. Mirov, V.P. Gapontsev, A.V. Erofeev, M.Z. Smirnov, G.B. Altshuler. In Frontiers in Optics 2012/Laser Science XXVIII, OSA Technical Digest (online) (Optical Society of America). 2012. FW6B.9. DOI: 10.1364/ASSL.2015.AW4A.1

[4] J.J. Adams, C. Bibeau, R.H. Page, D.M. Krol, L.H. Furu, S.A. Payne. Opt. Lett., 24, 1720 (1999).

[5] M.P. Frolov, Yu.V. Korostelin, V.I. Kozlovsky, Yu.P. Podmar'kov, Yu.K. Skasyrsky. Opt. Lett., 43, 623 (2018). 
[6] S.S. Balabanov, K.N. Firsov, E.M. Gavrishchuk, V.B. Ikonnikov, A.A. Sirotkin. Laser Phys. Lett., 16, P. 055004 (2019). https://doi.org/10.1088/1612-202X/ab09e87

[7] V.A. Antonov, A.A. Davydov, K.N. Firsov, E.M. Gavrishchuk, I.G. Kononov, S.V. Kurashkin, S.V. Podlesnykh, N.A. Raspopov, N.V. Zhavoronkov. Appl. Phys. B, 125, 173 (2019). https://doi.org/10.1007/s00340-019-7288-7

[8] K.A. Wickersheim, R.A. Lefever. J. Opt. Soc. Am., 1960. 50 (8), 831 (1960).

[9] R.K. Sackuvich, J.M. Peppers, N.-S.Myoung, V.V. Badikov, V.V. Fedorov, S.B. Mirov. Solid State Lasers XXI: Technology and Devices. Proc. of SPIE., 8235, 823520 (1-6) (2012). DOI: $10.1117 / 12.909156$

[10] V.V. Osipov, V.A. Shitov, K.E. Luk'yashin, V.V. Platonov, V.I. Solomonov, A.S. Korsakov, A.I. Medvedev. Quant. Electron., 49 (1), 89 (2019). https://doi.org/10.1070/QEL16797

[11] V.V. Osipov, V.I. Solomonov, V.V. Platonov, E.V. Tikhonov, A.I. Medvedev. Appl. Phys. A, 125, 48 (2019). https://doi.org/10.1007/s00339-018-2341-7

[12] Н.К. Морозова, И.А. Каретников, В.В. Блинов, Е.М. Гаврищук. ФТП, 35 (1), 25 (2001).

[13] A.F. Zatsepin, A.N. Kiryakov, D.A. Zatsepin, N.V. Gavrilov, B.L. Oksengendier. Vacuum, 175. 109243 (2020). DOI: $10.1016 /$ j.vacuum.2020.109243

[14] В.В. Осипов, В.В. Лисенков, В.В. Платонов. Письма в ЖТФ, 37 (1), 103 (2011).

[15] G.V. Samsonov, A.L. Borisova, T.G. Zhidkova. Physicochemical Properties of Oxides: Handbook (Metallurgiya, Moscow, 1978).

[16] В.В. Осипов, В.В. Платонов, В.В. Лисенков. Квант. электрон. 39 (6), 541 (2009).

[17] O.A. Zamyatin, V.G. Plotnichenko, M.F. Churbanov, E.V. Zamyatina, V.V. Karzanov. J. Non-Cryst. Solids. 480, 81 (2018). http://dx.doi.org/10.1016/j.jnoncrysol.2017.08.025 